\title{
Synthesis and Electrochemical Investigation of Oligomeric Ferrocene Amides: Towards Ferrocene Polyamides
}

\author{
Khaled A. Mahmoud, ${ }^{1}$ and Heinz-Bernhard Kraatz ${ }^{1,2}$
}

ERRATUM TO: JOURNAL OF INORGANIC

AND ORGANOMETALLIC POLYMERS AND

MATERIALS DOI: 10.1007/s10904-006-9040-0

The submitted and accepted dates for this paper were inadvertently omitted. The dates are as follows:

Submitted December 21, 2005; Accepted January 28,2006

The online version of the original article can be found at: http:// dx.doi.org/10.1007/s10904-006-9040-0

${ }^{1}$ Department of Chemistry, University of Saskatchewan, 110 Science Place, Saskatoon, SK, S7N 5C9, Canada.

2 To whom correspondence should be addressed.

E-mail: kraatz@skyway.usask.ca 